\title{
新疆天山南坡吐鲁番地区表土花粉的初步研究
}

\author{
王 力 $1,2,3$ 张 芸 $^{1^{*}}$ 孔昭宸 $^{1}$ 杨振京 $^{4}$ 阎 顺 ${ }^{5}$ 李月丛 ${ }^{3}$
}

${ }^{1}$ 中国科学院植物研究所植被与环境变化国家重点实验室, 北京 $100093 ;{ }^{2}$ 中国科学院大学资源与环境学院, 北京 $100049 ;{ }^{3}$ 河北师范大学资源与环境 科学学院, 石家庄 $050024 ;{ }^{4}$ 中国地质科学院水文地质环境地质研究所, 石家庄 $050061 ;{ }^{5}$ 中国科学院新疆生态与地理研究所, 乌鲁木齐 830011

摘 要 基于对新疆天山东段南坡吐鲁番地区选取的一条沿着海拔高度从 $2000--154 \mathrm{~m}$ 的不同植被带的植物群落样方进行 的调查及相应排序分析, 结合所采集的 36 个现代表土花粉样品的孢粉组合图式, 初步研究了吐鲁番地区的植被与表土花粉之 间的对应关系, 并将其与天山北坡的表土花粉谱进行了比较。结果表明吐鲁番地区表土花粉谱按照海拔高度自上至下可划分 为4个孢粉组合带, 分别对应于山地荒漠草原和荒漠带、戈壁砾石带、典型荒漠带以及盐沼植被带。与天山北坡的表土花粉 垂直带谱相比, 吐鲁番地区的花粉垂直带谱并不完整, 缺少典型的森林和蒿属(Artemisia)荒漠孢粉带。即使在相似的孢粉带, 吐鲁番地区的分布高度也高出北坡 $300 \mathrm{~m}$ 左右。典型的乔木植物云杉属(Picea)、松属(Pinus)花粉在风力和水流的作用下, 表 现出明显的超代表性; 用来指示干旱区半干旱区气候湿度变化的蒿属与䔉科花粉的比值能大致反映出荒漠带的典型特征。此 外, 研究区内表土花粉组合与环境因子之间的排序分析结果表明, 降水量是影响该区表土花粉组合的主要环境因子。与高属、 藜科花粉相比, 白刺属(Nitraria)花粉受降水量的影响较大。

关键词 吐鲁番地区; 表土花粉; 云杉; 天山; 新疆

引用格式: 王力, 张芸, 孔昭宸, 杨振京, 阎顺, 李月丛 (2017). 新疆天山南坡吐鲁番地区表土花粉的初步研究. 植物生态学报, 41, 779-786. doi: 10.17521/cjpe.2017.0019

\section{Preliminary study on pollen distribution in the surface soil of the Turpan region in the south- ern slope of Tianshan Mountains, Xinjiang, China}

\begin{abstract}
WANG Li ${ }^{1,2,3}$, ZHANG Yun $^{1 *}$, KONG Zhao-Chen ${ }^{1}$, YANG Zhen-Jing ${ }^{4}$, YAN Shun ${ }^{5}$, and LI Yue-Cong ${ }^{3}$
${ }^{1}$ State Key Laboratory of Vegetation and Environment Change, Institute of Botany, the Chinese Academy of Sciences, Beijing 100093, China; ${ }^{2}$ College of Resources and Environment, University of Chinese Academy of Sciences, Beijing 100049, China; ${ }^{3}$ College of Resources and Environment, Hebei Normal University, Shijiazhuang 050024, China; ${ }^{4}$ Institute of Hydrogeology and Environmental Geology, Chinese Academy of Geological Sciences, Shijiazhuang 050061, China; and ${ }^{5}$ Xinjiang Institute of Ecology and Geography, Chinese Academy of Sciences, Ürümqi 830011, China
\end{abstract}

\section{Abstract}

Aims Our main purposes were to analyze the relationship between vegetation and pollen in the surface soil of the Turpan region, which is located in the southern slope of the eastern Tianshan Mountains, and to compare different pollen assemblages between the Turpan region and the northern slope of the Tianshan Mountains.

Methods We collected 36 modern pollen samples and carried out modern vegetation survey in the Turpan region along an altitudinal gradient from $2000 \mathrm{~m}$ to $-154 \mathrm{~m}$. Detrended correspondence analysis and Redundancy analysis were applied to analyze the distribution pattern of pollen in surface soils.

Important findings We divided the pollen spectra into four pollen assemblage zones (mountain desert-steppe and desert, Gobi gravel, typical desert and salt mash vegetation), corresponding to the major vegetation types in the Turpan region. When compared with the northern slope, the characteristics of pollen assemblages in the mountain desert-steppe and desert were similar to those in the forest-steppe on the northern slope of the Tianshan Mountains; the pollen assemblages in the Gobi gravel and the typical desert seemed to be more consistent with those in the typical desert on the northern slope; however, no analogue was found in the salt mash vegetation. Obviously, the vertical pollen spectra in Turpan region were incomplete, lacking typical forest and Artemisia desert pollen zones. Besides, similar pollen zones in the Turpan region were found at an elevation of about $300 \mathrm{~m}$ higher than those in the northern slope. It is remarkable that the typical tree pollen, such as Picea and Pinus, showed their extra representation in the Turpan region. On one hand, the valley forest on the southern slope of the Tianshan mountains played an important role in pollen dispersal. On the other hand, with the cold air on the

收稿日期Received: 2017-01-21 接受日期Accepted: 2017-06-01

* 通信作者Author for correspondence (E-mail: zhangygl@ibcas.ac.cn) 
northern slope over the Tianshan Mountains, pollen may be carried and deposited in the Turpan region. The rivers feeding into Aiding Lake in the Turpan region may also contribute to the distribution of Picea and Pinus pollen. Lots of pollen studies have shown that the ratio of Artemisia to Chenopodiaceae (A/C) can be used as a good indicator of the degree of humidity in the semi-arid and arid areas. Our study revealed that $\mathrm{A} / \mathrm{C}$ can roughly reflect the characteristics of the desert zone in the study area. The results of Redundancy Analysis ordination on pollen assemblages and environmental factors (mean annual temperature (MAT), mean annual precipitation (MAP) and altitude (ALT)) revealed that MAP was the main environmental factor affecting the pollen assemblages in the surface soil in the Turpan region and had more significant effects on the distribution of Nitraria pollen than on the distribution of Artemisia and Chenopodiaceae.

Key words Turpan region; surface pollen; Picea; Tianshan Mountains; Xinjiang

Citation: Wang L, Zhang Y, Kong ZC, Yang ZJ, Yan S, Li YC (2017). Preliminary study on pollen distribution in the surface soil of the Turpan region in the southern slope of Tianshan Mountains, Xinjiang, China. Chinese Journal of Plant Ecology, 41, 779-786. doi: $10.17521 /$ cjpe. 2017.0019

孢粉作为研究全球变化的稳定代用指标, 在第 四纪的植被恢复和气候重建工作中发挥着重要作 用。要提高利用化石孢粉资料恢复古环境的准确度, 就必须加强表土花粉与现代植被之间对应关系的研 究。近年来统计学方法在狍粉-植被-气候的关系研 究中广泛应用, 不仅验证了表土花粉与现代植被之 间的关系(Wei \& Zhao, 2015; Zhang et al., 2017), 而且为利用现代花粉资料重建古气候提供了重要参 考(Schäbitz et al., 2013; Mauri et al., 2015)。

20 世纪 80 年代以来, 新疆地区的表土花粉研究 取得丰硕成果。较大范围的表土花粉分析结果表明 新疆地区不同植被带对应于不同的狍粉组合, 但花 粉浓度与其植被盖度的关系并非线性关系(Luo et al., 2009); 天山中部北坡的表土花粉研究结果显示 云杉属(Picea)花粉在上行风的作用下, 其分布高度 的上限高于云杉林植被, 藜科与蒿属(Artemisia)花 粉的分布同样受到上行风影响(Yang et al., 2016)。较 小尺度的表土花粉分析结果表明: 即使在荒漠及荒 漠草原表土中也有一定含量的云杉属(Picea)和松属 (Pinus)花粉(阎顺，1993; 阎顺等, 2004; 罗传秀等, 2008; Zhang et al., 2015a, 2015b)。

尽管新疆地区的孢粉研究成果显著, 但采样点 主要集中在天山以北地区。由于天山横亘于新疆中 部, 致使其南北自然环境截然不同, 表土花粉垂直 带谱间必然存在显著差异(许英勤等, 1996; 杨振京 等, 2011)。通过研究天山不同区域、不同沉积环境 中花粉组合的差异, 探讨其内在的动力机制, 进而 较准确地重建全疆的古气候和古植被, 为预测未来 气候变化提供理论依据, 很有必要加强对天山以南 地区表土花粉的研究。本文拟通过对吐鲁番地区 36
个不同海拔的表土花粉样品进行分析, 探讨该地区 表土花粉的垂直变化特征及其与植被之间的关系， 并与天山北坡的表土花粉组合特征进行比较, 为认 识全疆的古环境提供参考。

\section{1 材料和方法}

\section{1 研究区概况}

研究区吐鲁番地区位于天山东段, 地理位置为 $87.27^{\circ}-91.92^{\circ} \mathrm{E}, 41.20^{\circ}-43.67^{\circ} \mathrm{N}$, 是我国地势最低 的内陆盆地, 其三面环山, 盆地最低处的艾丁湖海 拔仅为-154.31 m。研究区气候为典型的暖温带干旱 荒漠气候, 年降水量 $16 \mathrm{~mm}$, 夏季平均最高气温在 38 “C 以上, 被称为“火洲”, 同时又有“风库”之称, 平均年大风日数在 100 天以上, 风力最高可达 12 级 (张新庆, 1998)。水系多发源于北部高山, 主要靠冰 雪融水及山区降水进行补给, 最终汇入艾丁湖(王 亚俊和吴素芬, 2003)。此外, 盆地内的植被垂直分 布规律具有明显的干旱环境植被特点, 由高到低分 别为山地荒漠草原和荒漠植被带、戈壁砾石带、典 型荒漠带以及盐沼植被带, 植被普遍稀疏矮小, 主 要优势种为驼线㢣(Ceratoides latens)、短叶假木贼 (Anabasis brevifolia)、大翅霸王(Zygophyllum macropterum)、膜果麻黄(Ephedra przewalskii)等。另外, 低 地草甸植被为隐域植被类型, 主要分布于农区外缘 至艾丁湖之间的平原低地, 植被为骆驼刺(Alhagi sparsifolia)群落。

\section{2 样品采集和鉴定}

在研究区从海拔 $2000 \mathrm{~m}$ 开始, 沿大河沿河、干 沟、煤窑沟每下降 $100 \mathrm{~m}$ 采集 36 个无人为干扰的表 土花粉样品(图1), 同时对样点进行植被调查及GPS

www.plant-ecology.com 
定位，最终到达艾丁湖附近。样品基本上按照海拔 高度顺序依次进行编号(表1)。

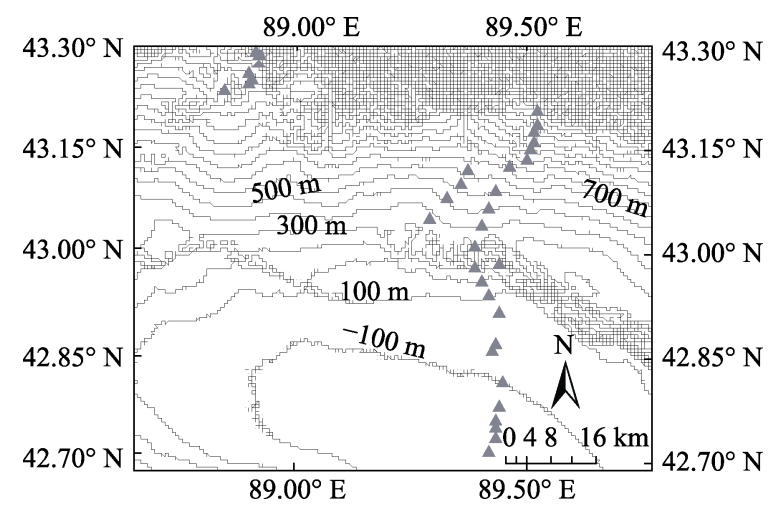

图 1 新疆吐鲁番地区表土花粉采样点。图中等值线上的 数字表示该处的海拔高度, 其间隔为 $100 \mathrm{~m}$ 。三角表示采 样点。

Fig. 1 Study area and locations of the pollen sampling sites in the Turpan region of Xinjiang. The contour lines represent elevation. The contour interval is $100 \mathrm{~m}$. The triangles represent sampling sites.

实验室取样50 g, 采用常规的酸碱处理及重液 浮选、醋酸䣶分解方法对花粉进行提取, 并在 Olympus 孢粉光学显微镜 (Olympus Corporation, Tokyo, Japan) $40 \times 10$ 倍镜下进行鉴定，除个别花粉 含量较少的样品外, 绝大多数样品均统计花粉 400 粒以上。

\section{3 数据处理}

以陆生植物花粉总数为基数, 计算各属种狍粉 百分比含量，并运用Tilia软件做出狍粉百分比图式 (图2)。将花粉组合中含量较高的花粉类型如云杉属 (Picea)、松属(Pinus)、麻黄属(Ephedra)、白刺属 (Nitraria)、禾本科、藜科、蒿属等典型花粉的百分 含量作为相应植被的孢粉数据矩阵, 通过Canoco软 件实现除趋势对应分析(DCA分析)。为进一步分析 表土花粉与环境因素之间的关系, 本文依据研究区 附近54个气象站点1960-2000年的年平均气温与年 降水量的平均值, 运用 $1 \mathrm{~km}$ 插值的方法(Hutchinson, 2006)建立36个采样点所对应的年平均气温和年降 水量。

\section{2 结果}

\section{1 孢粉组合特征}

36块表土花粉样品共统计花粉 13050 粒，分属 于 23 个植物科属, 均为新疆地区现生植被的陆生植 物区系成分。依据研究区地貌特征及现代植被调查 的相关资料，将该区表土孢粉谱划分为 4 个孢粉组 合带I、II、III、IV (图2)。

\subsubsection{I 山地荒漠草原和荒漠植被带 $(1000-2000 \mathrm{~m})$}

该带山地裸露, 主要优势种有盐穗木

表1 新疆吐鲁番地区各样品对应的海拔与现代植被带类型

Table 1 Altitude and vegetation zone of all samples from Turpan region of Xinjiang

\begin{tabular}{|c|c|c|c|c|c|}
\hline $\begin{array}{l}\text { 样号 } \\
\text { Sample }\end{array}$ & $\begin{array}{l}\text { 海拔 } \\
\text { Altitude (m) }\end{array}$ & $\begin{array}{l}\text { 植被带类型 } \\
\text { Vegetation zone }\end{array}$ & $\begin{array}{l}\text { 样号 } \\
\text { Sample }\end{array}$ & $\begin{array}{l}\text { 海拔 } \\
\text { Altitude (m) }\end{array}$ & $\begin{array}{l}\text { 植被带类型 } \\
\text { Vegetation zone }\end{array}$ \\
\hline 1 & 1990 & 山地荒漠草原和荒漠植被带 Mountain desert-steppe and desert & 19 & 500 & 戈壁砾石带 Gobi gravel \\
\hline 2 & 1936 & 山地荒漠草原和荒漠植被带 Mountain desert-steppe and desert & 20 & 400 & 戈壁砾石带 Gobi gravel \\
\hline 3 & 1850 & 山地荒漠草原和荒漠植被带 Mountain desert-steppe and desert & 21 & 400 & 戈壁砾石带 Gobi gravel \\
\hline 4 & 1700 & 山地荒漠草原和荒漠植被带 Mountain desert-steppe and desert & 22 & 260 & 典型荒漠带 Typical desert \\
\hline 5 & 1600 & 山地荒漠草原和荒漠植被带 Mountain desert-steppe and desert & 23 & 300 & 典型荒漠带 Typical desert \\
\hline 6 & 1500 & 山地荒漠草原和荒漠植被带 Mountain desert-steppe and desert & 24 & 220 & 典型荒漠带 Typical desert \\
\hline 7 & 1400 & 山地荒漠草原和荒漠植被带 Mountain desert-steppe and desert & 25 & 100 & 典型荒漠带 Typical desert \\
\hline 8 & 1300 & 山地荒漠草原和荒漠植被带 Mountain desert-steppe and desert & 26 & -45 & 盐沼植被带 Salt mash vegetation \\
\hline 9 & 1200 & 山地荒漠草原和荒漠植被带 Mountain desert-steppe and desert & 27 & -160 & 盐沼植被带 Salt mash vegetation \\
\hline 10 & 1300 & 山地荒漠草原和荒漠植被带 Mountain desert-steppe and desert & 28 & -180 & 盐沼植被带 Salt mash vegetation \\
\hline 11 & 1120 & 山地荒漠草原和荒漠植被带 Mountain desert-steppe and desert & 29 & -180 & 盐沼植被带 Salt mash vegetation \\
\hline 12 & 1100 & 山地荒漠草原和荒漠植被带 Mountain desert-steppe and desert & 30 & -90 & 盐沼植被带 Salt mash vegetation \\
\hline 13 & 1010 & 山地荒漠草原和荒漠植被带 Mountain desert-steppe and desert & 31 & -110 & 盐沼植被带 Salt mash vegetation \\
\hline 14 & 900 & 戈壁砾石带 Gobi gravel & 32 & -130 & 盐沼植被带 Salt mash vegetation \\
\hline 15 & 730 & 戈壁砾石带 Gobi gravel & 33 & -120 & 盐沼植被带 Salt mash vegetation \\
\hline 16 & 630 & 戈壁砾石带 Gobi gravel & 34 & -130 & 盐沼植被带 Salt mash vegetation \\
\hline 17 & 510 & 戈壁砾石带 Gobi gravel & 35 & -140 & 盐沼植被带 Salt mash vegetation \\
\hline 18 & 600 & 戈壁砾石带 Gobi gravel & 36 & -150 & 盐沼植被带 Salt mash vegetation \\
\hline
\end{tabular}




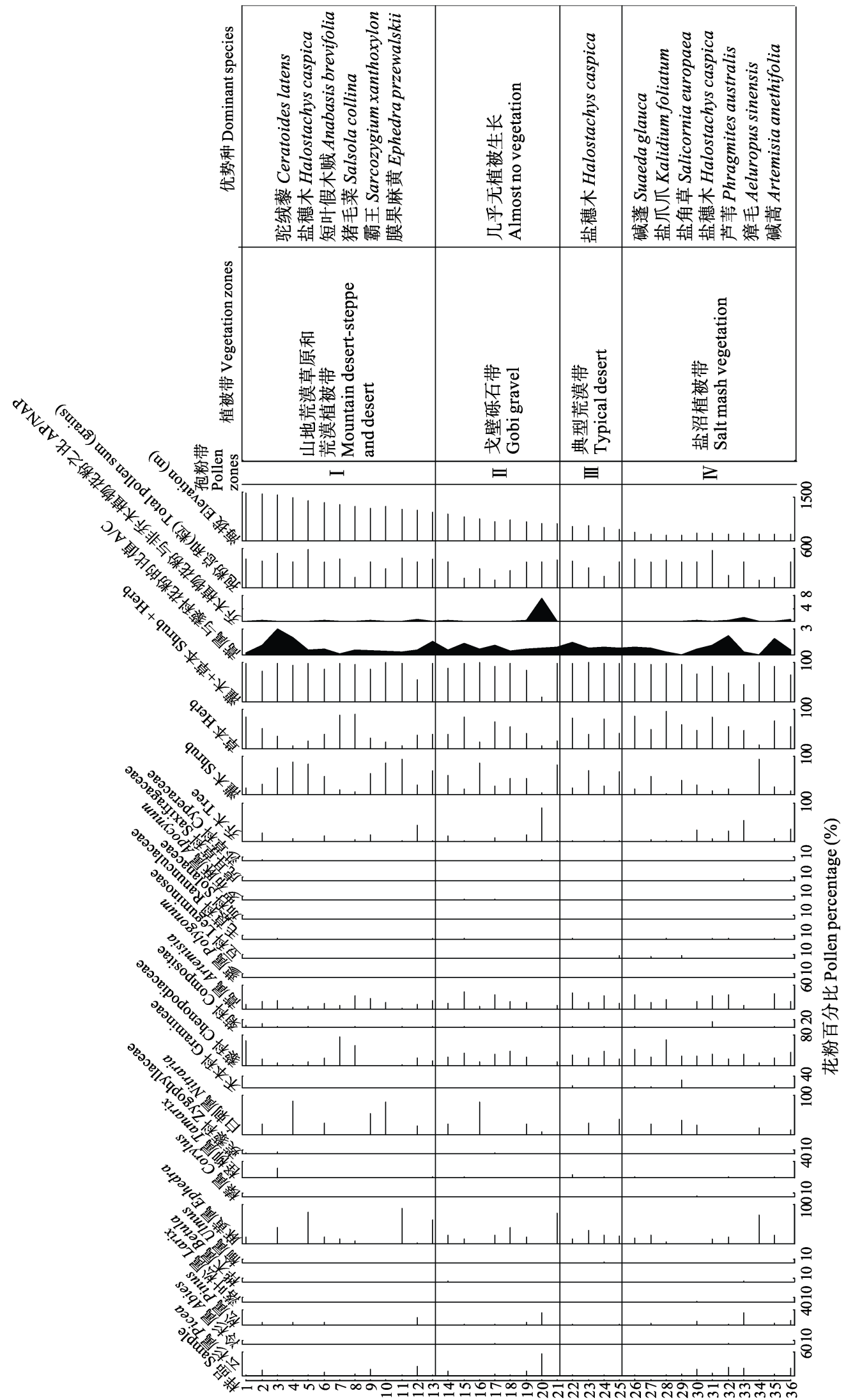

图2 新疆吐鲁番地区表土花粉组合图式。I, 山地荒漠草原和荒漠植被带(1 000-2 $000 \mathrm{~m})$; II, 戈壁砾石带(400-1 000 m); III, 典 型荒漠带 $(0-400 \mathrm{~m})$; IV，盐沼植被带(-154-0 m)。

Fig. 2 The pollen percentages and pollen zones in the surface soil in the Turpan region of Xinjiang. A/C, the pollen ratio of Artemisia to Chenopodiaceae; AP/NAP, the ratio of arboreal pollen to non-arboreal pollen. I, mountain desert-steppe and desert (1 000-2 $000 \mathrm{~m}$ ); II, Gobi gravel (400-1 $000 \mathrm{~m})$; III, typical desert (0-400 m); IV, salt mash vegetation (-154-0 m). 
(Halostachys caspica)、驼线藜、短叶假木贼、猪毛 菜(Salsola collina)、霸王(Sarcozygium xanthoxylon) 以及膜果麻黄等。狍粉组合中以麻黄属 $(25.2 \%)$ 、白 刺属 $(23.3 \%) 、$ 藜科 $(22.3 \%)$ 、蒿属 $(15.5 \%)$ 等旱生草 本和灌木植物花粉为主, 乔木植物花粉平均值占 $9.0 \%$, 其中云杉属花粉为 $5.8 \%$, 松属达 $3.2 \%$ 。麻黄 属和白刺属的花粉百分比含量均为整个孢粉谱的最 高值。该带蒿属与㴝科花粉的比值 $(\mathrm{A} / \mathrm{C})$ 较高 $(0.99)$, 乔木植物花粉与非乔木植物花粉之比(AP/NAP)却 较低(0.12)。

\subsubsection{II 戈壁砾石带(400-1 000 m)}

该带几乎无植被生长, 狍粉组合中灌木和草本 植物仍占优势 $(83.1 \%)$, 麻黄属 $(23.6 \%)$ 、藜科 (20.7\%)、白刺属 $(18.0 \%)$ 的花粉含量比带 $\mathrm{I}$ 少, 而蒿 属含量增至 $17.9 \%$ 。值得注意的是, II 带的乔木植物 花粉含量增至 $16.9 \%$, 云杉属花粉的平均含量 $(10.9 \%)$ 为整个孢粉带谱的最高值, 此外还见到少量松属花 粉等。尽管该带的 $\mathrm{A} / \mathrm{C}$ 值下降至 0.84 , 但 $\mathrm{AP} / \mathrm{NAP}$ 为 整个孢粉垂直带谱的峰值(0.94)。

\subsubsection{III 典型荒漠带 $(0-400 \mathrm{~m})$}

除绿洲外仅生长少量盐穗木等耐盐耐旱植物, 但河道或沟渠旁有杨(Populus)、榆(Ulmus)等阔叶树 生长, 并见牛皮消(Cynanchum auriculatum)、铁线莲 (Clematis florida) 等缠绕草本以及天山蒲公英 (Taraxacum tianschanicum)、大沙菄(Elaeagnus angustifolia)、芦苇(Phragmites australis)等植物, 植被 盖度高达 $70 \%$ 。孢粉组合中灌木和草本花粉的含量 达到最高 $(98.4 \%)$, 以蒿属 $(25.9 \%) 、$ 藜科 $(25.7 \%) 、$ 麻 黄属 $(21.4 \%)$ 及白刺属(17.4\%)为主。乔木植物花粉含 量大幅度下降至 $1.61 \%$, AP/NAP为孢粉带谱最低值 (0.02), 但 $\mathrm{A} / \mathrm{C}$ 值增至 0.98 。

\subsubsection{IV 盐沼植被带(-154-0 m)}

主要为芦苇-碱蓬(Suaeda glauca)盐碱沼泽, 伴 生种包括盐爪爪(Kalidium foliatum)、白梭梭(Haloxylon persicum)、盐角草(Salicornia europaea)、盐 穗木、獐毛(Aeluropus sinensis)、碱蒿(Artemisia anethifolia) 等。孢粉组合中灌木和草本植物花粉含 量下降至 $84.7 \%$, 以藜科(29.4\%)和蒿属(21.4\%)为主, 麻黄属(14.5\%)、白刺属(10.7\%)均下降至狍粉带谱的 最低值, 禾本科的百分含量略微上升至 $4.4 \%$ 。乔木 植物花粉含量大幅增至 $15.3 \%$, 其中, 云杉属和松 属花粉含量在海拔最低处分别高达 $19.8 \%$ 和 $12.4 \%$ 。
$\mathrm{AP} / \mathrm{NAP}$ 值有所增加, 为 0.25 , 但 $\mathrm{A} / \mathrm{C}$ 值降为 0.81 。

\section{2 排序分析}

DCA排序结果表明: 前两个排序轴的累积方差 贡献率可达 $52.9 \%$, 其特征值分别为 0.487 和 0.231 , 第 3 轴和第 4 轴的特征值分别为 0.081 和 0.050 , 显著 低于前两个轴, 这说明表土花粉数据和样品点的排 列主要受到第1轴和第2轴所代表的环境因素的控制, 梯度长度为 2.839 , 小于 3.0 , 故选择冗余分析(RDA) 分析方法进一步分析表土花粉数据与环境因素(年 平均气温MAT、年降水量MAP、海拔高度ALT)之间 的关系(图3)。

RDA 分析结果显示: 第 1 轴的特征值为 0.061 , 物种与环境相关性为 0.432 , 共解释了 $81.9 \%$ 的物种环境累计方差; 第 2 轴的特征值为 0.012 , 物种与环 境相关性为 0.228 , 共解释了 $97.5 \%$ 的物种-环境累计 方差。MAP、ALT与第二轴之间的相关系数均较高, 分别达到 0.89 和 0.84 , 但是各环境因子与第一轴的 相关系数均较低, 最高仅为 0.39 。

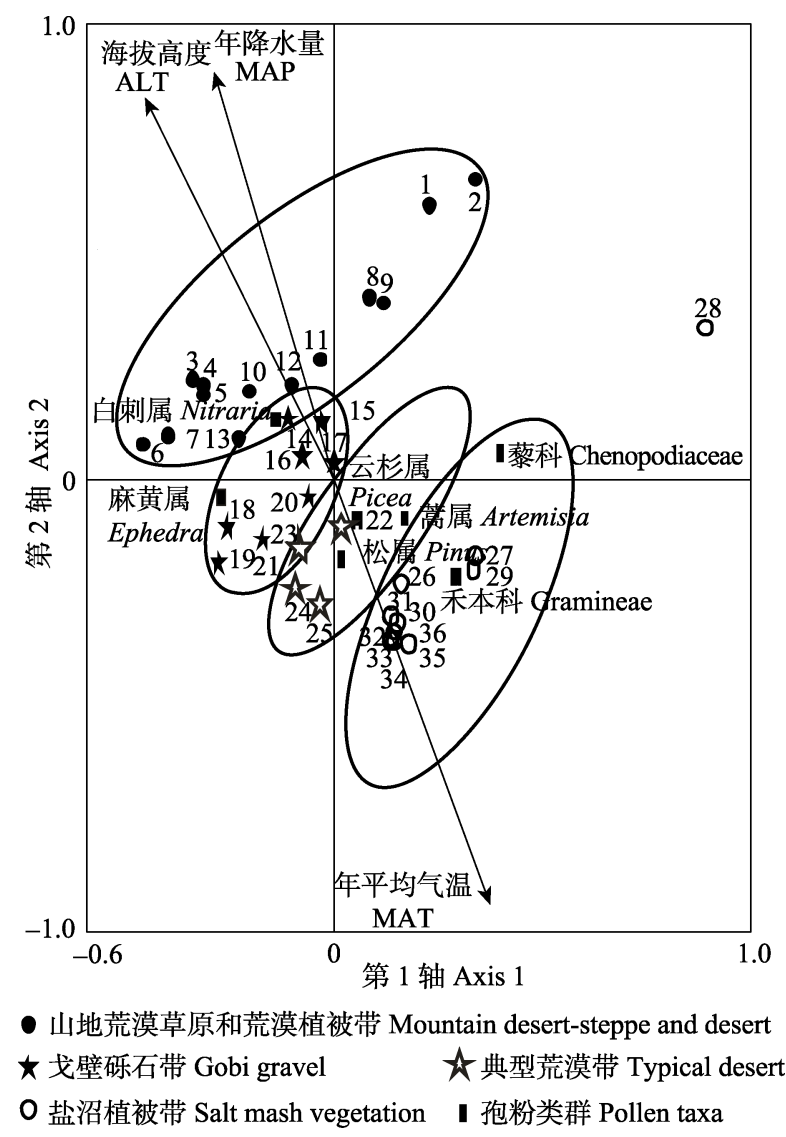

图3 主要花粉与样点的RDA排序图。

Fig. 3 RDA results of pollen sampling sites and pollen taxa. ALT, altitude; MAP, annual precipitation; MAT, annual average temperature. 
不同的植被带样品所对应的指示性花粉较为 明显, 与带I对应的为白刺属花粉, 带II主要与麻黄 属花粉相对应, 与带III对应较好的为蒿属花粉, 带 IV则主要对应于禾本科和藜科花粉。

\section{3 讨论}

\section{1 天山南坡吐鲁番地区表土花粉与植被的关系}

\subsection{1 典型乔木植物花粉与植被}

吐鲁番地区的乔木花粉类型以云杉属和松属 为主, 大量研究表明这两种花粉产量高且具备远距 离传播的能力, 常表现出明显的超代表性(李文渏 和姚祖驹, 1990; 阎顺, 1993; 罗传秀等, 2008; 张卉 等, 2013)。

带I山地荒漠草原和荒漠植被带云杉与松属花 粉含量高达 $23.75 \%$ 和 $18.00 \%$ 。根据文献记载, 南坡 海拔2 500-3 000 m的向阳石质坡处的针叶灌从中 可能存在松属的个别衍生种, 博格达山南坡海拔 2 400-2 $800 \mathrm{~m}$ 的个别山谷以及海拔2 100-2 $200 \mathrm{~m}$ 的河谷中分布有雪岭杉(Picea schrenkiana)(中国科 学院新疆综合考察队, 中国科学院植物研究所, 1978), 山谷风的下沉气流有可能把较高处的云杉 属和松属花粉搬运到该处沉积。另有一种可能是, 天山北坡的山谷上升气流非常强烈, 翻越天山分水 岭后气流下沉将云杉属和松属花粉携带在此沉积, 此种现象下文中将继续讨论, 其他学者的研究也证 实了类似现象的存在(杨振京等, 2011)。带 II 戈壁砾 石带几乎无植被生长, 却出现云杉花粉含量峰值, 这与该带样品孢粉浓度普遍较低(最低仅为 98.1 粒 $\cdot \mathrm{g}^{-1}$ ) 有一定关系, 新疆沙漠地区的表土花粉研究 也说明过类似现象(阎顺等, 2004)。值得注意的是, 带IV 盐沼植被带已距云杉林带很远, 但云杉属与松 属花粉的百分含量却较高, 这可能与吐鲁番是著名 的“风库”有关。春季吐鲁番盆地升温迅速, 产生较 大的气压梯度力, 高空受西北气流的强烈控制, 形 成偏北或西北风带, 冷空气大规模南下并翻越天山 分水岭。在南坡, 冷空气下沉, 流经盐山和火焰山时 流速加快形成狭管效应, 致使下风方向的吐鲁番市及 艾丁湖乡等地出现 8 级以上大风(张新庆, 1998), 近50 年的气象监测数据表明该区春季最高风速可达 250 $\mathrm{km} \cdot \mathrm{h}^{-1}$, 在此过程中, 北坡的云杉属及松属花粉便 被携带至此沉积。另外, 艾丁湖作为盆地中心, 汇集 了该区诸多河流及地下水, 这些河流都有可能把沿
途河谷区的云杉花粉携带在此沉积。因此对该区较 高含量的云杉属和松属花粉的解释应考虑水流和风 力作用。

\subsection{2 典型草本植物花粉与植被}

整个孢粉垂直带谱中的草本植物花粉以蒿属 和藜科为主, 其花粉产量高, 传播能力强, 在干旱 区表土花粉中常表现出超代表性(许英勤等，1996; 阎顺等, 1996; 李文渏，1998)。大量孢粉研究表明， $\mathrm{A} / \mathrm{C}$ 值可用来指示干旱半干旱区气候湿度的变化, 可用以区分草原和荒漠, 草原区其 $\mathrm{A} / \mathrm{C}$ 值一般大于 1 , 典型荒漠区则小于 1 ; 同时该比值在一定程度上也 反映了局域环境下人类活动对植被的干扰程度(ElMoslinmany, 1990; 孙湘君等, 1994; Zhang et al., 2010)。在本研究区中, 各狍粉带的 $\mathrm{A} / \mathrm{C}$ 值均小于 1 , 反映了荒漠带的典型特征。值得提出的是, 带 IV 的 $\mathrm{A} / \mathrm{C}$ 值极低, 这应与该带喜盐沼环境的藜科植物如 盐穗木、盐爪爪、白梭梭等较多有关, 尤其是 28 号 样品, 我们怀疑其采自人工种植的白梭梭纯群落, 其孢粉组合中䔧科花粉含量高达 $67.6 \%$, 反映出人 类活动对 $\mathrm{A} / \mathrm{C}$ 值会产生一定的干扰。

\section{2 天山南北坡表土花粉与环境因子的关系}

(1)编号为3-7、10-13的样品受ALT和MAP的影 响较大, 这些样品均属带I; 而26-35号样品与ALT 和MAP之间呈负相关关系, 但与MAT呈明显的正 相关关系, 这表明该带位于海拔最低处。本文所收 集的1960-2000年间气象数据表明降水量从盆地周 围的高山区向盆地中心递减, 年平均气温的变化趋 势则与之相反, 如西北部的高山冰雪区年降水量可 达400 mm, 但是海拔最低处的艾丁湖区年降水量 仅为 $1.1 \mathrm{~mm}$, 年平均气温却达 $15.4{ }^{\circ} \mathrm{C}$, 形成明显的 少雨和聚热中心。28号样品因为疑似采自人工种植 的白梭梭纯群落, 致使该样品孢粉组合与环境因子 之间的关系不明显。

(2)从盐沼植被带、典型荒漠带、戈壁砾石带到 山地荒漠草原和荒漠植被带, 随着ALT升高, MAP 逐渐增加, 反映了MAP和ALT的梯度变化; 并且 $\mathrm{MAP}$ 与第2轴存在着极显著的相关关系, ALT与第2 轴之间存在较显著的线性关系, 但第 1 轴反映的环 境梯度不是很明显, 所以MAP应是影响该区表土花 粉组合的主要环境因子。这就为利用该地区化石孢 粉组合重建古植被、古气候提供了现代狍粉学资料 和依据, 从而有助于古气候因子的解释和运用。 
(3)白刺属花粉含量受MAP因子的影响较蒿属 和萩科大, 这是因为白刺属植物作为典型的荒漠植 物区系中的优势种或建群种, 耐盐碱耐干旱, 广泛 分布于整个新疆地区，但在荒漠区河流沿岸阶地、 湖盆边缘以及山前洪冲积扇的扇缘带等地势较低, 而地下水位较高的盐化荒漠土或盐土中可成灌从状 分布(杜乃秋和孔昭宸，1983; 索有瑞，2010)。带IV 主要对应藜科和禾本科花粉, 这与盐沼植被带是以 碱蓬-禾草组成的盐化草甸为主的特征较为一致。

\section{3 天山南北坡样带表土花粉特征比较}

天山南坡地处背风坡，同时又受蒙古-西伯利 亚高压反气旋及塔里木盆地干热荒漠气候影响, 山 地明显旱化, 而北坡能够拦截北冰洋输送的湿润气 流, 植被垂直带谱较为完整。天山中段北坡可划分 为高山垫状植被狍粉带 $(>3400 \mathrm{~m})$ 、高山亚高山草甸 带(3 400-2 700 m)、山地云杉林带(2 700-1 720 m)、 森林草原过渡带(1 720-1 $300 \mathrm{~m})$ 、蒿属荒漠带 (1 300-700 m) 以及典型荒漠带 $(<700 \mathrm{~m})$ (杨振京, 2004)。与北坡相比, 吐鲁番地区植被垂直带结构趋 向简化, 垂直带谱不完整, 缺失连续成片的森林植 被带, 只在河谷等地存在片状针阔叶混交林。此外, 盆地环山带的内缘因洪水泛滥形成了以砾质为主的 洪积扇山前倾斜平原, 而后风力将细粒物质吹扬运 移, 形成典型的戈壁砾石带。艾丁湖外围平坦, 湖底 大量沉积厚层细粒盐土, 形成盐沼植被带。

天山南北坡的狍粉组合特征也有类似之处, 南 坡的山地荒漠草原带的花粉组合特征近似于北坡的 森林草原孢粉带; 戈壁砾石带和典型荒漠带的狍粉 组合特征则与北坡的典型荒漠带较为一致; 但是盐 沼带在北坡并不存在可类比的狍粉带。因此与北坡 相比, 该区缺失云杉林带以及蒿属荒漠孢粉带。另 外, 相同狍粉带在该区的分布高度要高于北坡, 典 型荒漠带在该区的分布高度高出北坡 $300 \mathrm{~m}$ 左右, 这可能与气候向南坡和东段渐趋旱化有关(胡汝骥, 2004), 即便是相同的狍粉带, 在天山东段和南坡分 布的海拔高度, 也比西段和北坡高出300-500 m。

\section{4 结论}

4.1 通过对新疆天山东段南坡吐鲁番地区海拔 $2000--154 \mathrm{~m}$ 采集的36个表土花粉样品进行狍粉 分析, 结合植被调查结果, 将表土花粉谱划分为 4 个 孢粉组合带, 分别对应山地荒漠草原和荒漠植被
带、戈壁砾石带、典型荒漠带和盐沼植被带。

4.2 吐鲁番地区与天山北坡的表土花粉组合特征 对比结果表明, 该区表土花粉垂直带谱不完整, 缺 少典型的森林和蒿属荒漠狍粉带, 即使相似的狍粉 带在该区的分布高度也要高出北坡 $300 \mathrm{~m}$ 左右。

4.3 表土花粉组合和环境因子的排序分析结果表 明, 降水量是影响该区表土花粉组合的主要环境因 子。表土中的云杉属和松属花粉与风力及水动力搬 运作用有较大关系; 白刺属花粉受降水量的影响较 蒿属和㢣科大。

基金项目 国家自然科学基金(41572331、41272386、 41372183和40601104)、中国地质科学院基本科研业 务费专项经费(YYWF201627)和教育部留学回国人 员科研启动基金。

致谢 感谢中国科学院新疆生态与地理研究所吐鲁 番沙漠(植物园)研究站在野外工作中给予的帮助。

\section{参考文献}

Comprehensive Expedition of Xinjiang, Chinese Academy of Sciences, Institute of Botany, Chinese Academy of Sciences (1978). Vegetation of Xinjiang and Its Utilization. Science Press, Beijing. (in Chinese) [中国科学院新疆综 合考察队, 中国科学院植物研究所 (1978). 新疆植被及 其利用. 科学出版社, 北京.]

Du NQ, Kong ZC (1983). Palynoflora of the Qarhan Saline Lake and its signification in geography and botany the spore-pollen assemblages from CK2022 drilling core at the Bieletan. Acta Botanica Sinica, 25, 275-282. (in Chinese with English abstract) [杜乃秋, 孔昭宸 (1983). 青海柴 达木盆地察尔汗盐湖的孢粉组合及其在地理和植物学 的意义. 植物学报, 25, 275-282.]

El-Moslinmany AP (1990). Ecological significance of common nonarboreal pollen: Examples from drylands of the Middle East. Review of Palaeobotany and Palynology, 64, $343-350$.

Hu RJ (2004). Physical geography of the Tianshan Mountains in China. China Environmental Science Press, Beijing. 338-339. (in Chinese) [胡汝骥 (2004). 中国天山自然地 理. 中国环境科学出版社, 北京. 338-339.]

Hutchinson MF (2006). ANUSPLIN Version 4.36 User Guide. Centre for Resource and Environmental Studies, the Australian National University, Canberra.

Li WY (1998). Quaternary Vegetation and Environment in China. Science Press, Beijing. 2-30, 43-48. (in Chinese) [李文渏 (1998). 中国第四纪植被与环境. 科学出版社, 北京. 2-30, 43-48.]

Li WY, Yao ZJ (1990). A study on the quantitative relationship between Pinus pollen in surface sample and Pinus vegetation. Acta Botanica Sinica, 32, 943-950. (in Chinese with 
English abstract) [李文渏, 姚祖驹 (1990). 表土中松属 花粉与植物间数量关系的研究. 植物学报, 32, 943950.]

Luo CX, Zheng Z, Pan AD, An FZ, Beaudouin C, Huang KY (2008). Spatial distribution of modern pollen in Xinjiang region. Scientia Geographica Sinica, 28, 272-275. (in Chinese with English abstract) [罗传秀, 郑卓, 潘安定, 安放舟, Beaudouin C, 黄康有 (2008). 新疆地区表土孢 粉空间分布规律研究. 地理科学, 28, 272-275.]

Luo CX, Zheng Z, Tarasov P, Pan AD, Huang KY, Beaudouin C, An FZ (2009). Characteristics of the modern pollen distribution and their relationship to vegetation in the Xinjiang region, northwestern China. Review of Palaeobotany and Palynology, 153, 282-295.

Mauri A, Davis BAS, Collins PM, Kaplan JO (2015). The climate of Europe during the Holocene: A gridded pollen-based reconstruction and its multi-proxy evaluation. Quaternary Science Reviews, 112, 109-127.

Schäbitz F, Wille M, Francois J-P, Haberzettl T, Quintana F, Mayr C, Lücke A, Ohlendorf C, Mancini V, Paez MM, Prieto AR, Zolitschka B (2013). Reconstruction of palaeoprecipitation based on pollen transfer functions-The record of the last 16 ka from Laguna Potrok Aike, southern Patagonia. Quaternary Science Reviews, 71, 175-190.

Sun XJ, Du NQ, Weng CY, Lin RF, Wei KQ (1994). Paleovegetation and paleoenvironment of Manasi Lake, Xinjiang, N.W. China during the last 14000 years. Quaternary Sciences, (3), 239-247. (in Chinese with English abstract) [孙湘君, 杜乃秋, 翁成郁, 林瑞芬, 卫克勤 (1994). 新 疆玛纳斯湖盆周围近 14000 年以来的古植被环境. 第四 纪研究, (3), 239-247.]

Suo YR (2010). Research and Development of Nitraria in Qaidam Basin. Science Press, Beijing. 113-116. (in Chinese) [索有瑞 (2010). 柴达木盆地白刺研究与开发. 科学出 版社, 北京. 113-116.]

Wang YJ, Wu SF (2003). Environment change over the Aydingkol lake region in Turpan Basin, Xinjiang. Journal of Glaciology and Geocryology, 25, 229-231. (in Chinese with English abstract) [王亚俊, 吴素芬 (2003). 新疆吐 鲁番盆地艾丁湖的环境变化. 冰川冻土, 25, 229-231.]

Wei HC, Zhao Y (2015). Surface pollen and its relationships with modern vegetation and climate in the Tianshan Mountains, northwestern China. Vegetation History and Archaeobotany, 25, 19-27.

Xu YQ, Yan S, Jia BQ, Yang YL (1996). Numerical relationship between the surface spore-pollen and surrounding vegetation on the southern slope of Tianshan Mountains. Arid Land Geography, 19(3), 24-30. (in Chinese with English abstract) [许英勤, 阎顺, 贾宝全, 杨云良 (1996). 天山南坡表土狍粉分析及其与植被的数量关系. 干旱区地理, 19(3), 24-30.]

Yan S (1993). The discussion on the pollen of pine family in surface soil in Xinjiang. Arid Land Geography, 16(3), 1-9. (in Chinese with English abstract) [阎顺 (1993). 新疆表 土松科花粉分布的探讨. 干旱区地理, 16(3), 1-9.]

Yan S, Jia BQ, Xu YQ, Yang YL (1996). The surface sampling of vegetation and pollen in the source area of the Ürümqi River. Journal of Glaciology and Geocryology, 18(Suppl.), 264-273. (in Chinese with English abstract) [阎顺，贾宝全，许英勤，杨云良 (1996). 乌鲁木齐河源 区植被及表土花粉. 冰川冻土, 18(增刊), 264-273.]

Yan S, Kong ZC, Yang ZJ, Zhang Y, Ni J (2004). Seeking relationship between vegetation and Picea pollen in surface soils of Xinjiang, northwestern China. Acta Ecologica Sinica, 24, 2017-2023. (in Chinese with English abstract) [阎顺, 孔昭宸, 杨振京, 张芸, 倪健 (2004). 表土中云 杉花粉与植被的关系. 生态学报, 24, 2017-2023.]

Yang ZJ (2004). Altitudinal Changes of Modern Pollen and Vegetation on the Northern Slope of the Mid-Tianshan Mt., Northwestern Dryland of China. PhD dissertation, Institute of Botany, Chinese Academy of Sciences, Beijing. (in Chinese with English abstract) [杨振京 (2004). 天山 中段北坡不同海拔高度的表土花粉与植被. 博士学位 论文, 中国科学院植物研究所, 北京.]

Yang ZJ, Zhang Y, Bi ZW, Yang QH, Kong ZC, Yan S, Yan MJ (2011). Surface pollen distribution in the southern slope of Tianshan Mountains, Xinjiang. Arid Land Geography, 34, 880-889. (in Chinese with English abstract) [杨 振京, 张芸, 毕志伟, 杨庆华, 孔昭宸, 阎顺, 严明疆 (2011). 新疆天山南坡表土花粉的初步研究. 干旱区地 理, 34, 880-889.]

Yang ZJ, Zhang Y, Ren HB, Yan S, Kong ZC, Ma KP, Ni J (2016). Altitudinal changes of surface pollen and vegetation on the north slope of the Middle Tianshan Mountains, China. Journal of Arid Land, 8, 799-810.

Zhang H, Zhang Y, Kong ZC, Yang ZJ, Li YM, Tarasov, Pavel E (2015a). Late Holocene climate change and anthropogenic activities in north Xinjiang: Evidence from a peatland archive, the Caotanhu wetland. The Holocene, 25, 323-332.

Zhang H, Zhang Y, Yang ZJ, Yan P, Kong ZC, Yan S (2013). Surface pollen research of Nanshan region, Shihezi City in Xinjiang. Acta Ecologica Sinica, 33, 6478-6487. (in Chinese with English abstract) [张卉, 张芸, 杨振京, 阎平, 孔昭宸, 阎顺 (2013). 新疆石河子南山地区表土花粉研 究. 生态学报, 33, 6478-6487.]

Zhang XQ (1998). Topography and weather in Turpan Basin. Bimonthly of Xinjiang Meteorology, 21(6), 11-13. (in Chinese) [张新庆 (1998). 吐鲁番盆地地形与天气. 新 疆气象, 21(6), 11-13.]

Zhang Y, Kong ZC, Wang GH, Ni J (2010). Anthropogenic and climatic influence on surface pollen assemblages along precipitation gradient in northeastern China. Global Ecology and Biogeography, 19, 621-631.

Zhang Y, Kong ZC, Yang ZJ, Wang L, Duan XH (2017). Surface pollen distribution from alpine vegetation in Eastern Tibet, China. Scientific Reports, 7, 586.

Zhang Y, Kong ZC, Zhang QB, Yang ZJ (2015b). Holocene climate events inferred from modern and fossil pollen records in Butuo Lake, Eastern Qinghai-Tibetan Plateau. Climatic Change, 133, 223-235.

责任编委: 梁存柱 责任编辑: 王 蒇

www.plant-ecology.com 


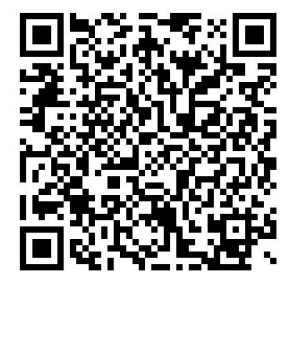

